\title{
Ametropias in Kinkala: Epidemiological and Clinical Aspects
}

\author{
Charles Géraud Fredy Nganga Ngabou 1,2, Chantal Makita1,2, Vissimy Onka ${ }^{1,3}$, \\ Koulimaya Reinette Messe Ambia², Benedicte Diatewa², Eyissa Gombe' ${ }^{1}$, Francine Alandzobo ${ }^{2}$ \\ ${ }^{1}$ University Marien Ngouabi, Brazzaville, The Republic of Congo \\ ${ }^{2}$ Department of Ophthalmology, University Hospital of Brazzaville, Brazzaville, The Republic of Congo \\ ${ }^{3}$ Clinic Ophthalmology, Brazzaville, The Republic of Congo \\ Email: fredygeraud@gmail.com
}

How to cite this paper: Nganga Ngabou, C.G.F., Makita, C., Onka, V., Messe Ambia K.R., Diatewa, B., Gombe, E. and Alandzobo, F. (2019) Ametropias in Kinkala: Epidemiological and Clinical Aspects. Case Reports in Clinical Medicine, 8, 301-306. https://doi.org/10.4236/crcm.2019.812037

Received: November 11, 2019

Accepted: December 20, 2019

Published: December 23, 2019

Copyright $\odot 2019$ by author(s) and Scientific Research Publishing Inc. This work is licensed under the Creative Commons Attribution International License (CC BY 4.0).

http://creativecommons.org/licenses/by/4.0/

\begin{abstract}
Ametropia is one of the leading causes of visual impairment. This study describes epidemiological and clinical aspects of ametropia as part of a free medical care program in Kinkala, Republic of Congo. Patients and Methods: We conducted a cross-sectional study from August 25th to September 24th, 2019; patients presenting complaints suggestive of ametropia were evaluated. The ametropia was determined by the objective method under cyclopentolate eye drops according to the following protocol: 3 applications of one drop every 5 minutes, followed by auto-refractometry at least 45 minutes after the first instillation. The auto-refractometer gave us the objective refraction. An anatomical examination was performed in order to eliminate any organic pathology. Results: Of the 2352 patients received, only 137 patients were included in our survey. Of the 137, 14 were emmetropic. Astigmatism was the most common ametropia. Its axis reversed with age, with more than $65 \%$ of direct astigmatism before age 40 . There was nearly $65 \%$ of reversed astigmatism at 60 years and over. In spherical equivalents, hyperopia accounted for more than $80 \%$ of ametropia. Conclusion: Ametropia in Kinkala is dominated by astigmatism. Spherical equivalent, hyperopia represents more than $80 \%$ of refractive error.
\end{abstract}

\section{Keywords}

Free Medical Care, Ametropia, Objective Refraction

\section{Introduction}

Ametropia is the most common cause of visual impairment worldwide and the second leading cause of blindness [1] [2] [3]. Unadjusted, they can affect school 
performance, reduce employability, productivity and generally affect the quality of life [1]. Its simple correction is reflected in the prescription of corrective lenses.

Countries in Africa are responsible for $1.1 \%$ to $7.9 \%$ of cases of visual impairment [4].

In Congo, studies have been tested on children [5] [6], but do not have data on the general population.

This study was conducted on the basis of data collected as part of a free consultation program in a region with shortage of adequate ophthalmic care.

\section{Patients and Methods}

\subsection{Patient}

We conducted a cross-sectional study in Kinkala, South Congo Brazzaville, as part of a free medical care program, in a mobile clinic.

Included in our study were patients over 5 years of age with no apparent organic disease. The study lasted one month, from 25 August to 24 September 2019.

\subsection{Method}

After registration, patients were complaining of a decrease in visual acuity or asthenopia, were placed on cyclopentolate eye drops according to the following protocol: 3 applications of one drop every 5 minutes. An auto-refractometry was performed at least 45 minutes after the first instillation, allowing us to determine the objective ametropia of patients.

Only static ametropias were taken into account in this study, presbyopia was not evaluated.

Only results greater than or equal to 0.5 dioptres (D) of spherical (hyperopia and myopia) or cylindrical (astigmatism) ametropia were considered.

The patients were then examined with a slit lamp to eliminate associated organic lesions.

Data analysis was done with epi-info software 7.

\section{Results}

Among the 2352 patients seen in ophthalmology, only 137 (5.82\%) were eligible for refraction, taking into account their original complaint;

Of the 137 patients (273 eyes, one patient being monophthalmic) examined, 14 (28 eyes) were emmetropic, and 123 patients (245 eyes) had ametropia.

Among patients with ametropia 42 were men versus 81 women. Or a sex ratio of 52 .

The prevalence of ametropia for all patients was 5.22\%.

Astigmatism was the most common ametropia in all age groups.

Among patients with astigmatism, 150 (86.71\%) had hypermetopic astigmatism, 17 (9.83) had myopic astigmatism, and 6 (3.47\%) had mixed astigmatism. 
The frequency of different types of ametropia was proportionally the same for both sex.

Astigmatism was direct or regular in $93(53.75 \%)$ cases, inverse or irregular in 56 (32.36\%) cases, and oblique in 24 (13.87\%) cases.

Between 5 and 15 , there was $71.43 \%$ of direct astigmatisms against $28.57 \%$ of inverse astigmatisms.

Between 16 and 39 years of age, there was $81.82 \%$ direct astigmatism, $10.61 \%$ inverse astigmatism and $7.58 \%$ oblique astigmatism.

Between 40 and 59 years, there was $38.55 \%$ direct astigmatism, $45.78 \%$ inverse astigmatism and 15.66 oblique astigmatism.

At age 60 and older, there was $11.76 \%$ direct astigmatism, $64.71 \%$ inverse astigmatism and $23.53 \%$ oblique astigmatism.

In spherical equivalent more than $80 \%$ of patients had hyperopia between 0 and $2.5 \mathrm{D}$.

\section{Discussion}

Cycloplegia in objective refraction is one of the methods used to detect ametropia. It is a bit more expensive because of the equipment it requires. It gives reproducible ametropia values, slightly higher than those obtained in subjective refraction [7].

Performing refraction only in patients with complaints about ametropia probably missed other ametropia.

Among the 273 eyes that benefited from objective refraction, in addition to the complete anatomical examination, 28 were emmetropic, which corresponds to a prevalence of ametropia of $5.22 \%$. This prevalence corresponds to African data [4].

The prevalence of ametropia varies from one study to another depending on the study population: children [8] or adults [9]; or the methodology used: some authors have considered ametropia from refractive values of 0.5 diopters [9] [10], and others from the value of 0.25 diopters [11].

The most frequent ametropia was astigmatism, with $70.61 \%$ of cases, followed by hyperopia with $25.71 \%$. Myopia accounted for only $3.67 \%$ of cases (Table 1 ). These results are close to those of Ebana [12] in Cameroon with $4.6 \%$ myopia and $51 \%$ hyperopia. We had a little more patients with astigmatism because of the use of the auto-refractometer which is a little more sensitive to the detection of astigmatism [7].

Hyperopic astigmatism accounted for $86.71 \%$ of astigmatisms versus $9.83 \%$ of myopic astigmatisms. These results are close to those of Ebana [12] in Cameroon with hypermetropic astigmatism at nearly $27 \%$ of all ametropia compared with nearly $9 \%$ of myopic astigmatism. Gargouri [13] in Tunisia had noted 59\% hypermetropic astigmatism versus $41 \%$ myopic astigmatism.

There was no difference in the frequencies of different types of ametropia by sex (Table 2). 
The axis of astigmatism evolved with age, between 5 and 39 years. More than $65 \%$ of patients had direct astigmatism, between 40 and 59 years of age. There was almost as much direct as there was reversed astigmatism. At 60 and over, reversed astigmatism was almost $65 \%$ of cases. This inversion of the axis of astigmatism with age had already been described in the literature [14]. Shah [15] who worked on adults noted a low prevalence of direct astigmatism (14\%).

Taking into account the spherical equivalent of different ametropia, $79.57 \%$ of our patients had hyperopia between 0.25 and 2.5 diopters (Table 3), which is consistent with Ebana [12] results in Cameroon, where hyperopia and astigmatism hyperopia accounted for $78.5 \%$ of patients.

Table 1. Distribution of patients according to the type of ametropia.

\begin{tabular}{ccccccc}
\hline & & \multicolumn{4}{c}{ Age } & \multirow{2}{*}{ Total } \\
\cline { 3 - 6 } & & $5-15$ years & $16-39$ years & $40-59$ years & Over 60 years & \\
\hline \multirow{2}{*}{ Astigmatism } & $7(46.66 \%)$ & $66(70.96 \%)$ & $83(70.94 \%)$ & $17(85 \%)$ & $173(70.61 \%)$ \\
Ametropia & Hypermetropia & $7(46.66 \%)$ & $25(26.88 \%)$ & $28(23.93 \%)$ & $3(15 \%)$ & $63(25.71 \%)$ \\
& Myopia & $1(6.66 \%)$ & $2(2.15 \%)$ & $6(5.12 \%)$ & - & $9(3.67 \%)$ \\
Total & & 15 & 93 & 117 & $20(100 \%)$ & $245(100 \%)$ \\
\hline
\end{tabular}

Table 2. Distribution of ametropia by sex.

\begin{tabular}{ccccc}
\hline \multirow{2}{*}{ Sex } & \multicolumn{3}{c}{ Ametropia } & Total \\
\cline { 2 - 4 } & Astigmatism & Hypermetropia & Myopia & \\
Males & $58(69.87 \%)$ & $22(26.5 \%)$ & $3(3.61 \%)$ & $162(100 \%)$ \\
Females & $115(70.98 \%)$ & $41(25.30 \%)$ & $6(3.7 \%)$ & 245 \\
Total & 173 & 63 & 9 & $2400 \%$ \\
\hline
\end{tabular}

Table 3. Distribution of patients according to the spherical equivalent of their ametropia.

\begin{tabular}{ccc}
\hline Optical results in Spherical Equivalent & number & $\%$ \\
\hline Ametropia $<-10 \mathrm{D}$ & 1 & 0.41 \\
Ametropia -10 to $-5 \mathrm{D}$ & 0 & 0 \\
Ametropia -5 to $-2.5 \mathrm{D}$ & 3 & 1.22 \\
Ametropia -2.5 to $-1 \mathrm{D}$ & 10 & 4.08 \\
Ametropia -1 to $0 \mathrm{D}$ & 34 & 13.88 \\
Ametropia 0 to 1 D & 143 & 58.37 \\
Ametropia 1 to $2.5 \mathrm{D}$ & 52 & 21.22 \\
Ametropia 2.5 to $5 \mathrm{D}$ & 2 & 0.82 \\
Ametropia $>5 \mathrm{D}$ & 0 & 0 \\
Total & 245 & 100 \\
\hline
\end{tabular}




\section{Conclusion}

Static ametropia in Kinkala, Congo, is dominated by astigmatism. The axis of astigmatism evolves with age, from direct astigmatism to childhood to inverse astigmatism in the elderly. Considering the spherical equivalent, hyperopia accounts for more than $80 \%$ of all ametropia encountered.

\section{Conflicts of Interest}

The authors declare no conflicts of interest regarding the publication of this paper.

\section{References}

[1] Resnikoff, S., Pascolini, D., Mariotti, S.P. and Pokharel, G.P. (2008) Global Magnitude of Visual Impairment Caused by Uncorrected Refractive Errors in 2004. Bulletin of the World Health Organization, 86, 63-70. https://doi.org/10.2471/BLT.07.041210

[2] Mansour, A.M., Kassak, K., Chaya, M., Hourani, T., Sibai, A. and Alameddine, M.N. (1997) National Survey of Blindness and Low Vision in Lebanon. British Journal of Ophthalmology, 81, 905-906. https://doi.org/10.1136/bjo.81.10.905

[3] Holden, B.A., Fricke, T., Ho, S., Wong, R., Schlenther, G., Cronje, S., et al. (2008) Global Vision Impairment Due to Uncorrected Presbyopia. Archives of Ophthalmology, 126, 1731-1739. https://doi.org/10.1001/archopht.126.12.1731

[4] Sherwin, J.C., Lewallen, S. and Courtright, P. (2012) Blindness and Visual Impairment Due to Uncorrected Refractive Error in Sub-Saharan Africa: Review of Recent Population-Based Studies. British Journal of Ophthalmology, 96, 927-930. https://doi.org/10.1136/bjophthalmol-2011-300426

[5] Makita, C., Nganga-Ngabou, C.G.F., Koulimaya, R.C., Diatewa, B. and Massamba, A. (2018) Ametropiain Children: A Review of 432 Cases. Ophtalmology Research: An International Journal, 8, 1-5.

[6] Adiba Fene, S., Nganga Ngabou, C.G.F. and Kilangalanga Ngoy, D. (2018) Les amétropies chez l'enfant en milieu urbain au Congo Brazzaville. Revue Africaine de Médecine et de Santé-Publique, 1, 35-39.

[7] Stoor, K., Karvonen, E., Liinamaa, J. and Saarela, V. (2018) Clinical Evaluation of Nidek Autorefractometer AR-360A. Acta Ophthalmologica, 96, 384-389. https://doi.org/10.1111/aos.13636

[8] Ayed, T., Sokkah, M., Charfi, O. and El Matri, L. (2002) Epidémiologie des erreurs réfractives chez les enfants scolarisés, socio-économiquement défavorisés en Tunisie. Journal Français do Ophtalmologie, 25, 712-717.

[9] Ezelum, C., Razavi, H., Sivasubramaniam, S., Gilbert, C.E., Murthy, G.V.S., Entekume, G. and Abubakar, T. (2011) Refractive Error in Nigerian Adults: Prevalence, Type, and Spectacle Coverage. Investigative Ophthalmology \& Visual Science, 52, 5449-5456. https://doi.org/10.1167/iovs.10-6770

[10] Abraham, E.G. and Megbelayin, E.O. (2015) Pattern of Refractive Errors among Ophthalmic Outpatients of University of Uyo Teaching Hospital, Uyo, Nigeria. Nigerian Journal of Ophthalmology, 23, 39-43. https://doi.org/10.4103/0189-9171.170965

[11] Onua, A.A., Pedro-Egbé, C.N. and Babatundé, S. (2012) Prevalence of Refractive Error in a Rural Ogoni Community in Southern Nigeria. Nigerian Journal of Oph- 
thalmology, 20, 30-32.

[12] Ebana Mvogo, C., Bella-Hiag, A.L., Ellong, A., Metogo Mbarga Njoh, B. and Litumbe, C. (2001) Les amétropies statiques du noir Camerounais. Ophthalmologica, 215, 212-216. https://doi.org/10.1159/000050861

[13] Gargouri, S., Kaibi, L., Sakka, M., Abib, L., Sallami, D., et al. (2017) La prise en charge optique des albinos en Tunisie. JIM Sfax, 25, 40-44.

[14] Lyle, W.M. (1971) Changes in Corneal Astigmatism with Age. American Journal of Ophthalmology, 48, 467-478. https://doi.org/10.1097/00006324-197106000-00002

[15] Shah, S.P., Jadoon, M.Z., Dineen, B., Bourne, R.R.A., Johnson, G.J., Gilbert, C.E. and Khan, M.D. (2008) Refractive Errors in the Adult Pakistani Population: The National Blindness and Visual Impairment Survey. Ophthalmic Epidemiology, 15, 183-190. https://doi.org/10.1080/09286580802105822 